\title{
DE LA VERDAD DE LA MENTIRA Y DE LA MENTIRA DE LA VERDAD
}

\section{ON THE LIE'S TRUTH AND THE TRUTH'S LIE}

\author{
Hermann Güendel Angulo ${ }^{1}$ \\ Universidad Nacional \\ hermann.guendel.angulo@una.cr
}

Recibido: 28/03/2017 - Aprobado: 16/09/2017

\begin{abstract}
Resumen
En este ensayo se explora el tema de la mentira y la verdad como un problema resultado de una interpretación prejuiciada sobre su presencia en nuestras relaciones cotidianas y en la organización de la sociedad. Se propone que para la superación de este nudo superestructural se acepte un nuevo tipo de abordaje, el cual, antes de ser moral y lógico formal, es más propiamente epocal, epistemológico, erótico y contextual.
\end{abstract}

Palabras clave: verdad, mentira, cotidianidad

\section{Summary}

This essay explores the topic of the lie and the truth as a problem resulting from a prejudiced interpretation of their presence in our daily relationships and social organization. It proposes the acceptance of a new type of approach in order to overcome this superstructural knot, which, as apposed to being moral and formally logical, is rather epochal, epistemological, erotic and contextual.

Key words: Truth, Lie

\section{Introducción del problema}

La verdad no es más que un postulado carente de fundamento ontológico. Lo que llamamos verdadero es tan solo un cascarón relleno de

1 Máster en Filosofía por la Universidad de Costa Rica, autor de artículos de opinión en el Semanario Universidad de la UCR y de ensayos especializados en la Revista Espiga de la UNED, Praxis de la UNA y la Revista de Filosofía de la UCR. 
supuestos. Justificada su existencia por exigencias morales provenientes de una religiosidad represiva, se pretende que la verdad sea una, única, absoluta, universal. Se trata así de una apelación ontológica a lo esencial, lo substancial, que se propone asentada en una relación entre el sujeto y el objeto. Relación epistemológica primera que es, por demás, insuficiente, pues al sujeto de conocimiento no se le enfrenta sino a través de mediciones diversas, políticas, ideológicas, religiosas, morales, todas ellas tan solo epocales. Las mediaciones que conectan al hombre con su realidad no son sino de carácter histórico, por ello transitorio, dando por resultado que las conclusiones a las que arriba la inteligencia no son sino relativas al momento histórico que sustenta las mediciones que lo vinculan al objeto que pretende entender, quedando entonces la verdad de ese objeto sometida a la contingencia del tiempo histórico de mediación. Toda verdad es un postulado emergente del momento en el que se enuncia.

Ese momento, constituido por diversidad de lugares de enunciación, define la perspectiva de realidad desde la que el sujeto se coloca. Y no es más que eso, perspectiva. No enfrenta el espíritu al objeto en su totalidad orgánica, en su ser como tal; no trata así con un objeto real, sino con la realidad de una perspectiva.

Es un ángulo posible, eso es todo, y sobre ello se enjuicia creando el piso sólido de supuestos verdaderos que requiere para vivir, pues la vida le exige certidumbres. Es esto lo que exalta a las almas más bellas con el heroico furor del aliento de un dios. Esa es la efímera base desde la que se gesta el esfuerzo de la lógica formal, para dar cuenta de su solidez por medio de razonamientos que al final no son sino formalizaciones de juegos de palabras. La lógica occidental, logocéntrica y formal no puede dar cuenta ni del tema de la verdad, ni del de la mentira. Previo a la verdad que valida, esta no es verdadera, pues carece del sólido cimiento de ser, para tan solo fundamentarse en un transitorio estar, una perspectiva mediada por condiciones de lugar y momento, situación cultural y particularidad histórica, científica, tecnológica y política.

Esa verdad, que se estudia y exige, cuyas formas de enunciación se definen, no es sino una exigencia de una existencia desventurada, incapaz de soportar sobre sí el cambio de los tiempos. El esfuerzo formal por entender la forma del razonamiento verdadero siempre será un vulgar pasatiempo, pues 
la relación epistémica que podría fundamentar todo su empeño se escapa de lo lógico, como se escapa la neblina entre los dedos del niño que juega a agarrarla.

Mediado gnoseológicamente por relaciones complejas entre múltiples factores, lo verdadero no es más que una certidumbre epocal, sustentada en las condiciones superestructurales de la época. En esta nuestra época, la verdad no es sino un postulado moral distorsionado por la palabrería de conciencias pedantes que requieren de escaparates donde pavonearse. Así, la verdad, nuestra verdad epocal, no tiene peso ontológico, sino ético. No tiene firmeza epistémica, sino histórica. No es condición de la vida, sino parte de la forma de vivirla. Toda verdad es una mentira, toda mentira es una verdad, lo único que las separa es la argumentación que respalda a cada una, o que las deja en orfandad.

El imaginario cristiano ha figurado progresivamente, a lo largo de siglos, un escenario particular como punto de partida de esa incuestionable forma de enunciar y valorar un discurso que se pretende verdadero. El de la verdad de la fe revelada por el maestro. La verdad de la realidad espiritual. El tiempo de la verdad es el tiempo histórico, es época cultural que delimita lo que se impone como manera convencional de proferir una verdad, y la divorcia de lo que se convenciona como mentira. El sustento de la verdad es solo la eventualidad histórica producida por el hombre.

El tiempo histórico de imperio ético y epistémico de la verdad en la cristiandad, la verdad sin ontología, solo arribará tras siglos de imposiciones. El cristianismo no es una realidad espiritual, sino cultural e histórica. Fruto de elaboración ingeniosa, responde más a la necesidad de explicar lo que aquel silencio del maestro dejó sin resolver, que lo que el pueblo de dios necesitaba vivir. El cristianismo se transformó en dogmática de concilios, saturada de sincretismos y formulaciones discursivas. Impuestas por el fuego, la cárcel y la condena a muerte, las certezas de la cristiandad se constituyeron en evidentes convenciones.

Nació entonces una forma de pensar asociada a una forma de actuar. Nació el régimen cristiano de la verdad. Una gnoseológica unida a una ética. Tras el paso de los siglos, la debilidad de los argumentos de la Iglesia dio lugar a las armas como lógica de acallamiento de todo otro modo de pensar y actuar. El hedor de los cadáveres paganos perfumó el régimen de validación 
creado por la cristiandad y lo consolidó durante siglos. De los argumentos de fuerza nacieron las conversiones, su modo de pensar y condena, de enunciar la verdad y considerarla. Nacieron las formas lógicas de consignar la certeza de lo que se dice, como exigencia de coherencia al enunciar la verdad.

Mas si no por la fuerza, esa forma de pensar y enunciar, restrictiva por el entramado de sus reglas y procedimientos deductivos e inductivos, habría sido abandona por el ejercicio de la inferencia y la analogía diaria. La lógica no es sino condición procedimental del modo cristiano de pensar, enunciar y diferenciar. Como tal padece de la misma ausencia de sustento ontológico que su matriz histórica. Por ello, en ella la forma desplaza el contenido material que tan solo supone desde afirmaciones prejuiciosas sobre el ser y la no contradicción. Las coordenadas categoriales del régimen cristiano de validación y afirmación de la verdad de los iniciados dio lugar a condiciones formales de enunciación y argumentación, exigibles aún a los paganos. Bajo el juego de particulares y universales, la verdad devota dio lugar a la inteligencia estudiosa.

El cristianismo creó certezas, no sobre la base de una ontología, sino de una elaboración discursiva. De esta se desprendió un tipo específico de proceder lógico, que responde a ese régimen y sus postulados, aún en una sociedad laica. El antiguo régimen de una única verdad, que nos hace libres, que es evidente por ser divina, que ciega toda otra consideración gnoseológica y ontológica, solo se preserva como prejuicio de almas minias. Hoy podemos afirmar que sus verdades son solo convenciones impuestas por la fuerza, el miedo y la superstición. Su lógica no es más que un juego de procedimientos carentes de la firmeza de las diversas formas de existir, pensar, valorar e interpretar. La lógica logocéntrica, desarrollada en Occidente, es tan solo una normativa procedimental de enunciación que corresponde a las cadenas categoriales del ámbito superestructural de la cristiandad. Por ello, padece de sus vacíos y prejuicios, y no puede dar cuenta de los otros modos de pensar y de ser que enriquecen nuestro complejo mundo actual.

\section{Cotidianidad de la verdad y la mentira}

La mentira está presente de una manera u otra dentro de las diversas relaciones de cotidianidad: la amistad, el encuentro causal, las relaciones 
amorosas y de seducción, la convivencia matrimonial y, con igual fuerza, tanto dentro de la configuración de la opinión pública como en la percepción de los distintos procederes gubernamentales de los poderes de la república. Es importante abordar su significado, sentido e incidencia sobre estas diversas relaciones, desde un enfoque que dé cuenta de la complejidad de este fenómeno humano en las vivencias, un enfoque que se separe de valoraciones dicotómicas.

Se considerará a la enunciación de la mentira como un aspecto recurrente en la cotidianidad de nuestras relaciones filiales, de intimación y vinculación casual, cuyos alcances prácticos, o sentido, atraviesan las diversas relaciones humanas, tanto aquellas de carácter inmediato como aquellas mediatas o sociopolíticas, desde una perspectiva de valoración que se circunscribe a lo vivencial y político, guardando distancia del lugar ético, o tradicional de interpretación. El universo ideológico logocéntrico occidental asume la tradición moral normativa cristiana que impone una valoración específica de la mentira como exclusión de la verdad, y asocia necesariamente la interpretación de ella en contraposición a la verdad.

Al definir la mentira como ausencia de la verdad, el pensamiento dicotómico de la cristiandad configura, en la región superestructural de la cultura, una aproximación exclusivamente peyorativa, reduciendo, desde ello, su valoración a una condena ética en contra de lo que es de modo más general un falso testimonio intencional. Reducida a esto, la mentira se divide, según su esencia, o bien en ironía, o en acallar algunas cosas, o bien en manifestar lo que se pretende bajo el disfraz de una bondad reconocida. La mentira se ve así como propia de aquel que, siendo de algún modo irresponsable, recurría al engaño a través de la simulación o la hipocresía.

Vista desde la dicotomía, verdad en oposición a la mentira, la recurrencia a la mentira refiere a una personalidad viciosa, propia del que vive mintiendo, ya de modo espontáneo o por mera conveniencia. El mentir transgrede entonces, moralmente, las condiciones de relación filial dentro la comunidad, siendo, por tanto, origen de distorsiones conductuales diversas como la desconfianza, ruptura en la fluidez de la intimación humana, y precipitando, de todo modo imaginable, la irrupción del sentimiento de culpa, aún y cuando la mentira fuera piadosa antes que impía. 
Es particularmente interesante notar como san Agustín aportó, en su momento, una visión compleja del tema de la mentira, relegada luego a un segundo plano, hablando en su momento de tipos distintos de mentira. Para él, las distintas formas de la mentira podían ser las que se presentan en la enseñanza religiosa, las que hacen daño y que no ayudan a nadie, las que no hacen daño y ayudan a alguien, las mentiras que surgen por mero placer de mentir, las mentiras dichas para complacer a los demás, las mentiras que engañan, las que no engañan, las que pueden salvar la vida de alguien, las que protegen la pureza de alguien. El pensamiento agustiniano introducía, efectivamente por lo expuesto, una aproximación al tema desde una valoración circunstancial al tema pero, sin duda, igualmente reductiva a lo ético. Pues en el fondo, Agustín consideraba como acto de mentir a aquel en el que se oculta, de diversos modos, una verdad. ${ }^{2}$

Y solo es esa intención de ocultamiento el origen de la mentira, en sus diversos grados y funciones, de tal modo que es la intención humana de ocultamiento, y no el acto de enunciación como tal, la que se debería someter al juicio éticamente sustentable. Ocultar se entendía en profunda oposición a la verdad, convirtiendo a aquel que enunciaba la mentira en un trasgresor de oficio, ante el cual la actitud no podía ser otra sino la del recelo circunstancial, y desconfianza permanente. Sin embargo, iquién no ha recurrido en algún momento de su existencia, al enfrentarse a alguna situación, persona, o exigencia social, a usar alguna mentira? Todos los seres humanos, en algún momento de nuestra vida, ya por acción o por omisión, por intención o por contexto, hemos recurrido a enunciar una mentira.

Buscando proponer un nuevo lugar de interpretación, no se asume la percepción maniquea que reduce mentir simplemente a la ausencia de verdad en lo que enunciamos hacia otro. No hay un tal perfil conductual como el de un mentiroso patológico. No hay una personalidad exclusiva particular de aquel a quien podemos llamar mentiroso. Las mentiras se presentan en nuestra vida cotidiana como reacción emocional y relacional a un contexto conductual, en el cual las condiciones de seguridad y confianza

2 San Agustín en su obra Contra la mentira había elaborado una comprensión particular de la mentira en la cual se encuentra la entremezcla de censura y perdón. Se categoriza la mentira en formas voluntarias, involuntarias, dañinas y hasta piadosas. Si se es suspicaz se nota que al final el patrístico vislumbraba ya la indiferencia entre la verdad y la mentira, pero le era imposible, por artículo de fe, exponerlo. Si su dios es asiento de la verdad no puede oponerse al imperio del régimen divino de validación. 
se nos escapan de las posibilidades de comprensión y dominio. Así, no se trata solamente de una declaración realizada por alguien con una intención engañosa. La mentira es un acto complejo, donde la enunciación se refuerza con una práctica. Posee, entonces, tanto condiciones lógicas de enunciación como condiciones antropológicas, sociales y culturales particulares de validación, que hacen inefectiva una consideración única, obligando al filósofo actual a considerarla como un fenómeno que se expresa de múltiples modos, igualmente válidos y efectivos, irreductibles a la valoración desde una ética normativa.

Se miente tanto al ser amado como al odiado; al cercano como al lejano. Se miente aun cuando se esté obligado a decir la verdad, y aun si la verdad fuera la salida más simple a un dilema en la vida. Hay mentiras que al escucharlas nos resultan tan carentes de coherencia, que solo dan lugar a la burla. Otras tan veraces que solo pueden ser asumidas como una verdad indudable. La mentira es una elaboración compleja, consciente y mucho más complicada que la verdad. Su validación no se encuentra solo en el modo de enunciarla, sino también en la actitud del que enuncia, considerando la posibilidad de comprensión y aceptación de su enunciado. La mentira posee su propia estética, su nobleza, como escribiera Maquiavelo en El príncipe.

Resulta obvio que las aproximaciones reductivas y simplistas, propias de una cristiandad laica que actúa como superestructura, en la sociedad costarricense actual, no pueden dar cuenta de un fenómeno cuyos alcances, presencia y significado trascienden las fronteras del individuo, su identidad y relaciones de cotidianidad. La mentira se presenta en todos y cada uno de los ámbitos posibles de las relaciones de vivencia que enfrentamos en la cotidianidad. Tiene, en cada uno de ellos, alcances, significados y sentidos específicos, poseedores de funcionalidad diferenciable a tal grado que no puede someterse tan solo a una judicialización moral, sino que exige otra perspectiva, integral e integrada, metodológicamente transdisciplinaria. Así, la insuficiencia del abordaje valorativo ético-normativo y dicotómico, al no dar cuenta de esta diversidad de lugares o momentos, así como de condiciones de enunciación, no dimensiona la importancia y valor funcional de la mentira.

Entender esto desde su complejidad, sin definición única y una valoración reductiva al precepto, desembocando en estudios de casos particulares 
que reflejen periodos de manejo de la opinión pública y las condiciones de gobernabilidad dentro de ellos, conlleva a la finalidad de desarrollar una aproximación crítica para comprender la recurrencia y los alcances que posee la mentira. No ha de ser considerada a priori como excepción, ni regla, sino como un aspecto más de los que se presentan en la cotidianidad de las relaciones de filiación e intimación que vivimos diariamente. Con ello, y para lograr una aproximación crítica que nos separe del lugar común normativo de censura y condena inquisitoria, el tema de la mentira, la recurrencia a ella, su significado y sentido, no ha de abordarse desde el presupuesto de que ella, por sí misma, genere conflicto. La mentira no necesariamente perturba la fluidez de las relaciones y su estabilidad, ni provoca ruptura en los encuentros casuales; por el contrario, constituye un rango específico de condiciones de vinculación entre quienes se aproximan y se abren a la expectativa de relacionarse con alguna constancia.

La mentira aparece en la cotidianidad como nexo, como espacio de efectividad para aquel tipo de encuentro donde la simulación aparencial despierta interés o disimula repugnancia. De este modo, se concibe a la mentira como una construcción compleja que incide en las relaciones filiales, constituyendo un aspecto más en el encuentro entre sujetos específicos para hacerlo sometible en condiciones de vivencia segura. Por ello Nietzsche creía que necesitamos seguir mintiendo, permitir que ciertos errores y artículos de fe permanezcan intactos en nosotros, con la condición de que nos mantengan con vida. La mentira no se construye en modo intuitivo y arbitrario, sino concienzudamente con base en las condiciones que se enfrentan vivencialmente, y que son uno de los aspectos que otorgan gran credibilidad narrativa y significado práctico en las relaciones de convivencia. Constituye entonces una creación atenta a circunstancias referidas, comprensibles, y con ello se valida, a priori, como poseedora de la fuerza propia de una verdad que se acepta.

Bien preguntaba Nietzsche

¿Qué es entonces la verdad? Su respuesta tajante, es tan solo una hueste en movimiento de metáforas, metonimias, antropomorfismos, en resumidas cuentas, una suma de relaciones humanas que han sido realzadas, extrapoladas y adornadas poética y retóricamente, y que después de un prolongado uso, se 
les considera firmes, canónicas y vinculantes. Las verdades son ilusiones de las que se ha olvidado que son, metáforas se han vuelto gastadas y sin fuerza sensible (1973, p. 5).

El escenario en el que irrumpe la mentira nunca es simple. Está constituido así por sujetos y situaciones diversas, por sí mismas complejas, de tal modo que se miente con más habilidad al conocido que al desconocido, a quien solo se le engaña, mientras que el primero se distrae en el acontecimiento. El otro se abre a la mentira por las condiciones de percepción del mundo en el que se constituyen las relaciones de vinculación, siendo entonces, más que acto de ingenuidad propia, un acto de despreocupación hacia las intenciones de los demás. Por ello, no podemos atenernos a lo objetivo, pues en el fondo, para sobrellevarlo, el ser humano habrá de mistificarlo, de someterlo al anhelo de lo controlable.

El motivo de la enunciación de la mentira no ha de ser reducido al sujeto, o al mundo que se complica, sino al enfrentamiento con este mundo, en tanto desborda las condiciones que permiten a una persona permanecer tranquila en la vinculación con los diversos otros. La existencia se puede vivenciar en mil formas diferentes, oscilando entre la belleza y la tragedia. Un mundo complejo es un mundo de simulación, disimulo y apariencias, que se vivencian como buenas costumbres.

Pero, contrario a lo que en el vox populi corre, es la necesidad del omnibus dubitare. Nos es necesario desconfiar de las razones por las que el otro se aproxima a nosotros para conocer de sus intenciones. Esto es lo que, al final de todo, incorpora el conflicto de la mentira a nuestra existencia, antes de sacarlo de ella, la expectativa de la desconfianza. La razón de proximidad ya enunciada nos expone con mayor facilidad a la maledicencia de los otros que a la buena voluntad de nosotros. Se miente a los otros, se distrae al nosotros, se le oculta la intención, hasta que logre recuperar su función en el mundo. La mentira es subterfugio de quien tergiversa su existencia para recuperar el aliento de la vida, la pule, la corrige, la restablece en el curso de su mundo. La mentira ensancha un mundo que se estrecha para aquel que lo vivencia. No es un acto egoísta sino, en ocasiones, altruista. Se miente en ocasiones para decir una verdad; para acercar al otro y hacerlo partícipe de la danza 
seductora del encuentro íntimo y filial. Se propone entonces que la mentira enunciada es más compleja que la verdad expuesta.

Enunciar una mentira supone la consideración de relación entre espacio y tiempo más allá del inmediato lugar y momento, así el precepto epistemológico es base para la enunciación de la mentira. Contrario a las presunciones de las buenas costumbres, el ser humano miente más tiempo del que se pasa diciendo la verdad. La mentira es vivencia de una metáfora en la existencia que se aproxima, con creatividad, a la vida, a la creación de un mundo habitable. Un mundo complejo solo tiende a la identidad consigo mismo, a generar una estética de su caos. Poética de las metáforas que sustentan aproximaciones recelosas, propias de seres que ansían abrazar la ilusión del todo enfrentando, tan solo, la parte. La moralidad aquí no radica en el precepto normativo, sino en las condiciones de vivencia del nosotros, y su vinculación al encuentro con los otros, buscando, siempre, simplificar lo complejo, lo agobiante, lo confuso.

Escribió Nietzsche

Somos nosotros quienes hemos inventado por las causas, interdependencias, el número, la ley, la libertad, y cuando leemos este mundo de signos en las cosas como algo realmente existente y mezclado con ellas estamos haciendo lo que siempre hemos hecho, es decir, mentir (1973, p. 12).

Parto entonces de que la enunciación discursiva de la mentira es un acto de racionalidad articulado con base en una lógica de alegorías y de subterfugios, cuya belleza es propia de los logros de la imaginación práctica, poética y creativa. La mentira es poiesis del mundo perceptible cuando este se vacía de belleza, siendo, con ello, predicado de la belleza en su ausencia. La irrupción de la mentira se gesta mediada por la complicación de la existencia, en tanto esta sale del refugio estrecho del mundo de sí mismo, para vincularse al del nosotros y, finalmente, al de los otros. Con ello se propone, como aspecto del marco teórico de la investigación, que el uso de la mentira va más allá de la inseguridad que nos provoca nuestra mala crianza. La lógica interna de la mentira es lógica de la retórica y de la vivencia; se constituye dentro de los límites de la lógica que regula el lenguaje, se fundamenta a priori en ella y se deriva de ella, fundamentando su credibilidad no en el discurso mismo, sino 
en el sentido vivencial que se asocia a una significación enunciativa. Se trata a la lógica de la mentira como una lógica intuitiva de la apariencia fundante de vínculos, a veces resultan transitorios, a veces recurrentes.

La persistencia de la mentira supone una práctica relacional continua. Se puede mentir a través de la verdad selectiva, bajo el peso ya de intereses o de circunstancias específicas y, sin embargo, será perenne, en todo caso, la necesidad de apaciguar las incertidumbres con las que nos aturde la vorágine de nuestro desconcierto. Así, para hacer creíble una mentira es necesario ocupar lugares y momentos con actos consecuentes con lo enunciado. Solo es mentira aquello que se enuncia asociado a una situación práctica. Frente al simplismo reductivo de la ética normativa ha de recuperarse el postulado agustiniano de que no hay una única forma de mentir, sino diversas, tipos distintos de mentira con sentido y significado distinto. No puede aceptarse el prejuicio usual en el sentido común social de que opinar sin conocimiento de causa es mentir, esto no es sino grosera expresión de estupidez. La inteligencia siempre media en la enunciación de la mentira, como requisito para enriquecer, creativamente, el curso del mundo con la constante conspiración de la imaginación creativa.

El mayor riesgo de mentira radicaría así en complicar la evidencia que se pretende simplificar, ya que la percepción de la mentira desemboca en desconfianza, por ello complica el mundo de quien la enuncia, y desencanta el mundo de quien la devela. Es el desconfiar permanentemente, como recelosa actitud moral, lo que incorpora el desagrado de la mentira en nuestra existencia, no la mentira misma. La mentira trasciende entonces el espacio personal de encuentro filial, se integra de esta manera a relaciones de poder, control y dominio. Lo vivencial se vuelve social, la condición estructural se transforma en superestructural. La eficacia de la mentira en la existencia cotidiana la traduce en recurso político eficaz. Considerada ahora como recurso político, la mentira no puede ser abordable de manera normativa, sino dentro de consideraciones propias del ejercicio del poder y su estética. En el escenario de las relaciones de gobernabilidad occidentales, la mentira, como recurso político, aparece asociada a la configuración del totalitarismo contemporáneo. Dirigiéndose no solo a la masa, sino al enemigo, tanto potencial como franco, provoca condiciones idóneas para que la opinión pública dé lugar al consenso cívico. 
La mentira política no solo supone la concepción del arte político, sino también del ser humano mismo. Su uso se dirige a crear condiciones de percepción de hechos, en tanto reconfigurados en acontecimientos, para regular el ejercicio de la gobernabilidad en una sociedad escindida por sus contradicciones y decadencia. Reflexionar filosóficamente es hacer pensamiento sistemático de la ilusión del mundo que se vivencia, que no se separa de, sino que sigue su curso por otro medio, no el del discurso acostumbrado ético y dicotómico, sino el del discurso que se organiza con la palabra del rebelde. La rebeldía es el acto de osadía propia de aquellos que nos atrevemos a ser libres.

\section{Para reinterpretar la distinción entre la verdad y la mentira}

La mentira es solo un discurso, como lo es la verdad. Estos discursos son herramientas de convivencia y supervivencia a los que cualquiera puede recurrir ante las eventualidades de su vida. Ya sea para su bien o para el bien de los otros. Así, lo que se llama verdad o mentira no es ni lo uno ni lo otro, sino lo que para uno u otro confronta su alma en el movimiento aturdidor de la vida diaria. Cierto es que aún vivimos bajo el peso del prejuicio cristiano, su lógica, sus supuestos, censura y castigos. No en balde las condiciones superestructurales nos llevan a autocensurarnos cuando, intencionalmente, recurrimos a lo que creemos interpretar, en este momento, como mentira, aun cuando solo se hace un juicio moral carente de una gnoseología plenamente sólida.

El sujeto que miente intencionalmente se piensa a sí mismo como merecedor de castigo, y se expone a este en la inconsistencia de su falta. En el ámbito superestructural de la cristiandad, el hombre que miente desea solucionar su pecado, así aparece ante el que miente como incoherente, lo que dice y hace empata. El manejo de los tiempos y actitudes, la conservación del discurso se abandona. Sus expresiones gestuales y acciones se dispersan en multiplicidad de imposturas particulares. Surge de ello la presunción de definir la personalidad del mentiroso (Ekmann, 2009) como si esta conducta fuese una forma de ser y no solo una actitud situacional. El mentiroso es mentiroso, como el borracho lo es; pero todos nos emborrachamos, tanto 
o más como todos creemos decir verdades y mentiras, y con eso no somos mentirosos o sinceros.

Se requiere una nueva aproximación no teñida por el prejuicio ético para entender la recurrencia en la cotidianidad de lo que se pretende sea mentira o verdad. Una gnoseología diferente que nos aproxime a las motivaciones y circunstancias cotidianas de las relaciones humanas. Mentir, tanto como decir la verdad, es parte de la actividad diaria. Se presenta en mayor o menor medida en todos los asuntos del hombre. Su presencia indigna a algunos, reconforta a otros. Se trata de la ambivalencia en la construcción del nosotros al que recurrimos para gozar de nuestro mundo. Aproximarnos al desconocido es un acto de seducción. El gesto y la palabra conforman un puente entre el otro y el yo tendiente a construir un nosotros. Mas ese otro es incierto, exige condiciones de aproximación y requiere condiciones de seguridad en esa aproximación. Se trata de desarrollar un vínculo; pero no conocemos el modo efectivo de hacerlo.

Se le escucha, se le mira, nuestro yo se descentra y solo con expectativas vuelve su presencia hacia nuestro espacio, ambos somos imágenes, ambos somos expectativas. Ambos estamos ocultos tras los ropajes de formalismos y buenos modos, pero dispuestos a la develación. Es ahí cuando, desnudos, nos encontramos con que los supuestos pierden importancia y se inicia el eterno recorrido de conocernos. En la filiación diaria recurrimos a las convencionales verdades y mentiras, a las reglas de enunciación cultural encerradas en la época con el mismo objetivo, construir con otros el nosotros reconfortante. Así, no hay ni hombres mentirosos o sinceros, sino solo seres humanos, demasiado humanos como para no adecuar la realidad del mundo a los simples requisitos del encuentro, ser seductores para los otros hasta donde podamos retenerlos.

Nuestra inteligencia interviene a nuestro favor, crea recursos de encuentro, desarrolla sus esfuerzos en rumbo a la ficción por la cual nos vinculamos. Nuestro intelecto crea ilusiones para el encuentro intenso, pasajero o duradero, por las horas o los años que transcurran, y las llama vivencias, dolorosas algunas, otras no. El encuentro social humano es un acto de ficción. Se adula, se enmascara, se devela lo que encubre al giro convencimiento del otro. En la síntesis entre el gesto y la palabra, la verdad y el deseo son uno. Deseamos solo las consecuencias agradables del discurso. Aquellas que 
preservan el placer de la vida, indiferentes ante exclusiones de naturaleza epistemológica, lógica y de consideración ética. Las actuales diferencias entre la verdad y la mentira no nos han de importar, nos ha de importar la proximidad que nos permiten durante el tiempo que esta perdure. No hay, pues, diferencias profundas, ontológicas y gnoseológicas que nos perturben, sino solo un ámbito equivalente de vivencias.

Pero, ¿cómo convivir con quien solo miente o con quien dice solo la verdad? El placer de la compañía, de su cuerpo, de su sexo no es asunto de verdad ni de mentira, sino de aceptación de nuestra compañía. No nos aproximamos en la verdad o en la mentira, sino en las condiciones que mutuamente aceptamos como condición de filiación. Entonces, ¿qué es la verdad, qué es la mentira en nuestra vida diaria? Un conjunto de intenciones que se expresan en metáforas, de relaciones de significado creadas en la artificialidad del mundo desarrollado por el hombre. Adorables unas, groseras otras, según el interés de la aproximación cuando alguien nos interesa; o del divorcio cuando nos estorba. Podemos decir lo que creemos una verdad o una mentira para acercarnos o para alejarnos. Las verdades, tanto como las mentiras, son ficciones de encuentro. Complejas construcciones verbales y gestuales, enunciadas de modo comprensible por nuestra voz y cuerpo. Metal moldeado a la usanza de la sociedad por la que se le considera como moneda, pero que es tan solo un pedazo de metal (Nietzsche, 1973).

En el encuentro con lo diverso nuestro cerebro recurre a lo que es necesario para garantizarnos la sobrevivencia y el sexo. En nuestro cerebro la llamada neocorteza se encarga de razonar, interpretar y hacer asociaciones de pensamiento (Navarro, 2012). De ahí la recurrencia a enunciados que puedan valorarse como falsos o verdaderos. No responde a un tipo de personalidad, ni a una suerte de maledicencia moral, sino a una actividad cerebral específica en el enfrentamiento a condiciones que comprometan la supervivencia de la persona y la especie. Así, ni la verdad ni la mentira son tales, sino enunciaciones que se organizan por arte de nuestro cerebro como una interpretación de la realidad, de acuerdo a la situación de supervivencia que encierre al sujeto. Justo es por ello que ni el abordaje moral ni el lógico puedan dar cuenta del problema de diferenciar ontológicamente la verdad y la mentira, y que se requiere más bien de una aproximación más rica y 
compleja que supere el fundamentalismo epistémico que conserva aún el prejuicio de la verdad absoluta.

Nuestro cerebro construye y asimila sus conceptos a través del lenguaje recurrente en la socialización, y desarrolla sus juicios más usuales como corolario de esto (Navarro, 2012). Con el paso de los años actúa como la abeja, limpia las viejas celdas del panal para llenarlas con nueva miel, amplía su panal como lo hace el hombre con su mundo. De manera preventiva, nuestro cerebro protege al hombre para que no se frustre con las condiciones de su realidad. Nos encontramos entonces en la situación misma de la mentira y la verdad, son tan solo recursos relacionales asociados a la sobrevivencia y vivencia cotidiana.

Aparte de consideraciones éticas, no existe realmente ningún supuesto gnoseológico, ni antropológico, que legitime su divorcio. La realidad histórica es ambivalente y ambigua, ante ella el recurso del lenguaje nos permite crear refugios, ordenamientos, subterfugios, evasiones y reconocimientos, salidas elegantes a todas las condiciones del difícil encuentro con otros, ante lo cual, en muchas ocasiones, morimos de vergüenza. Recurrir a lo que se cree es la mentira en la vida diaria no es pues un acto de ignorancia, de engaño, de estupidez o mediocridad. Es un ejercicio de inteligencia para la sobrevivencia del ser humano, que le exige por lo demás un profundo razonamiento. Tanto mentir como decir la verdad son arte sabio, patrimonio de la humanidad en propiedad privada de nuestra vida. Hay pues nobles mentiras como viles verdades, mentiras verdaderas y verdades mentirosas. Fue Platón el primero en darse cuenta de ello. Argumenta a favor del pseudos, en el libro tercero de La República, como instrumento para mediar en las relaciones entre gobernantes y gobernados, y entre los gobernados mismos, o vislumbrar la naturaleza de la recurrencia a ambas formas de discurso en nuestra vida.

Ambas son necesidades para el buen vivir. Invaden por ello la política y la cultura, al alma buena y a la compleja maraña de relaciones en la que sobrevivimos dentro el mundo. ${ }^{3}$ En nuestra vida diaria la recurrencia al discurso afianza el compromiso de los hombres con el bien necesario de la realidad sociopolítica en la que subsisten. Así expuesto, no es del tiempo dorado de la filosofía, sino de la oscuridad del cristianismo patrístico desde

3 Véase para ello, si se conserva alguna duda, el brillante capítulo tercero de La república de modo integral. 
donde la mentira se desnaturaliza. Fue san Agustín el padre de la consideración cultural de la verdad en su clave moral. Manteniendo que toda mentira es en el fondo un acto pecaminoso, sin importar el grado o intención, que él mismo diferencia. Será san Agustín quien marque una línea divisoria entre la noción griega clásica y la que hasta hoy arrastramos.

La verdad agustiniana no acontece, no es la altheia griega, sino la identidad con lo revelado tras la enseñanza del maestro. Jesús no es para él un simple profeta, es un filósofo divino. Para Agustín la verdad radica en su dios, es por ello emergente de una experiencia, una verdad revelada a través de la persona real de Jesús, el Cristo. Es desde ahí que la mentira se identifica con una infracción moral de la verdad de dios y de la ley. El actual mundo laico solo ha logrado sustituir un término por otro; ahí donde la presencia de dios sustenta la verdad y sus normas, se ha colocado el orden jurídico del que se deriva toda norma, todo valor. Visto así, la enunciación de la verdad es un deber cívico. Una catarsis para el alma del ciudadano y una exigencia para el buen gobernante.

Mas la verdad enunciada es tan solo un discurso que se organiza desde una perspectiva funcional para ambos. La inteligencia política crea sus verdades y sus mentiras con el único objetivo de resguardar la unidad social. Al lado de esa necesidad política se encuentra, como lo observara Platón, la necesidad antropológica, abrir nuestro mundo a la convivencia social. Por ello es que no solo en ciertas ocasiones, sino en todo momento, la recurrencia a una mentira en sentido estricto, o sea aquel discurso que carece de condiciones socioculturales de validación, responde a la misma razón de la enunciación de una verdad estricta, o sea la que se posiciona como tal según el régimen de validación que le resulta orgánico epocalmente. La enunciación de verdades y mentiras en el límite estricto de las condiciones epistémicas epocales de enunciación actual es situacional, simple expectativa de subsistencia al encuentro con el otro y el mundo. La verdad y la mentira son recursos situacionales utilizados dentro de las condiciones que percibe nuestro cerebro para asegurar nuestra supervivencia, física, cultural, en síntesis, integral. Esto significa que tanto la presencia recurrente de la verdad y la mentira dentro de relaciones de cotidianidad constituyen vehículos de comunicación y encuentro dirigidos a la constitución de escenarios 
complejos de relaciones sociales gratificantes al menos en expectativa, o sea dignas de ser vivenciadas.

Nuestro espíritu entreteje su mundo dentro de delimitaciones funcionales epistémicas y lógicas, que se asocian a conductas de encuentro e intimación, es decir, a conductas moralizadas. El entretejido de esas relaciones se conforma por medio de discursos y signos que siguen una lógica propia, la misma de cualquier discurso. ${ }^{4}$ La recurrencia a enunciados verdaderos o falsos aparece entonces como un elemento colateral de las relaciones humanas diarias, central cuando se trata de la sobrevivencia del sujeto y su intimación sexual. La convivencia con otros requiere que nuestra inteligencia desarrolle para sí afirmaciones propias que le garanticen compañía y sexo. Con ello se abre una posibilidad, la de que el discurso mismo sea su propio régimen de validación en tanto entre en juego la intimación sexual-social. De este modo, bajo prioridades de vinculación emocional-sexual, todo tipo de discurso, ya el que se considera falso como el que se le valora como verdadero, se asocia, junto a todo lo expuesto anteriormente, a la vinculación corporal humana.

Esta nueva posibilidad funcional asociada a lo que todo ser humano requiere para vivir alegremente el dulce placer de la piel de otro, hasta que nos exaspere o nos canse, se encuentra en el mismo rango de resultados efectivo para la sobrevivencia y convivencia de la racionalidad epocal que nos condiciona. ${ }^{5}$ Con ello, como lo señala Simmel en su obra, ${ }^{6}$ la mentira posee densidad. ${ }^{7}$ Esta condición es la de constituir una acción comunicativa que favorece la vinculación y, por tanto, la arquitectura en la enunciación del discurso. Lo que se dice y lo que no, lo que se afirma o niega, posee en sí mismo directividad comunicativa, no una línea divisoria real. La suposición de la lógica y la ética imperante en la cristiandad resulta ser ahora irrisoria. En el momento de la vinculación interpersonal lo que se cree verdad puede pasar a ser mentira, tanto como lo que se cree mentira puede pasar a ser verdad.

4 Foucault realizó en su momento un profundo estudio del tema concluyendo en la existencia de condiciones externas e internas de discurso que lo hacen creíble, o sea verdadero, estas condiciones conforman la episteme epocal, lo que acá he insistido en llamar régimen de validación. Véase su obra titulada El orden del discurso.

5 Escribe M. Foucault: "La racionalidad se ha impuesto y es poseedora de poder. Por ello ha sido ella quien ha marcado los criterios, parámetros y valores predominantes en Occidente" (La verdad y las formas jurídicas, p. 125).

6 Simmel, G. (2006). Introducción. En Sociología, p. 12

7 Simmel refiere con este término a una suerte de forma sociológica que posee valor por encima de su contenido, o sea, sin importar que lo que se postule en un enunciado sea verdadero o falso, lo que importa es el efecto social que este posee en términos de vinculación entre sujetos específicos. 
Las relaciones de vinculación humanas son dinámicas, sus particularidades y supuestos cambian con los años. Por ello exigen variaciones discursivas y gestuales en las cuales el vínculo previo se afiance en algo más sólido que la emoción vana del amor y la belleza del cuerpo. Así entendido, es fácil comprender por qué se puede iniciar una relación con otro con una "verdad", o una "mentira", pero no se puede sostener o terminar esa misma relación con la misma "verdad" o "mentira". El problema es en el fondo que el otro perciba esa "verdad" o "mentira" como enunciado comprensible dentro de la delimitación de significados existentes. Es muy usual que el otro asuma lo que decimos en un sentido distinto al que pretendemos, incluso en no pocas ocasiones se puede llegar al extremo de entender totalmente lo opuesto. Con ello los diversos discursos a los que recurrimos en nuestra cotidianidad son valorables, no desde lecturas lógicas o éticas, sino desde reacciones sociológicas visibles como prácticas de aproximación, cohabitación y coexistencia. ${ }^{8}$

Los diversos discursos se validan o excluyen según condiciones epocales de la organización superestructural de comprensión de nuestras vivencias. Estas condiciones constituyen la arquitectura de las vinculaciones, intimaciones y filiaciones, no tienen sustento ontológico, sino social e histórico reflejado en actitudes morales. La mentira como la verdad, los discursos que se configuran desde la episteme epocal que nos define como sujetos culturales, aparecen ahora como requisito favorecedor de la coexistencia ante su permanente transitoriedad.

Con todo lo anterior, la vieja epistemología, la lógica y la normativa moral solo constituyen arcaísmos. Entender hoy cómo se constituyen las tan necesarias condiciones de seguridad para garantizar la vinculación emocional y física con los otros es reconfigurar la visualización misma de la identidad humana. No se es quien se es en la soledad de nuestra conciencia, sino que en la mirada que despertamos en otros se encuentra la dimensión de nuestra afirmación y autoestima. El "mentir" es tan exigible socialmente como el decir la "verdad". Reaccionando, sin embargo, bajo el prejuicio de la moral cristiana nos separamos del placer que nos genera el alago, con la convicción de que hemos hecho el bien y somos merecedores de la salvación divina. El

8 Creo con ello haber entendido plenamente el argumento de Simmel sobre este tema, no con sus palabras, sino con mis conclusiones a partir de sus ideas. Véase para ello el capítulo segundo de su obra citada anteriormente. 
viejo prejuicio moral cristiano es vano al confrontarse con el simple hecho de que necesitamos garantizarnos la obtención de intimación, de reconocimiento, encuentro con otros, y no solo con nuestros genitales.

Al otro no le importa si nuestros enunciados discursivos son "verdades" o "mentiras", lo que importa es que lo seduzcan, que lo obliguen a abrirse a quien ha conseguido que se acerque a él. La vinculación humana es una experiencia social de la corporalidad, se atiene tanto a instintos y deseos como a condicionamientos culturales y jurídicos, lo que la conciencia ingenua llama moral es resultado de lo político, de la centralización de conductas. Esta compleja normatividad producida por la imposición de una reglamentación en común configura al ser humano en sujeto epocalmente específico, y unifica diversas comunidades en un ámbito orgánico común, la sociedad que vivimos y su definición de realidad histórica.

El hombre enfrenta de este modo diariamente un escenario artificial pero múltiple de relaciones sociales, o sea impersonales. En tanto somos sujetos epocales particulares, portadores de esta forma específica de ser en sociedad, rozamos cotidianamente diferentes comunidades, el hombre se vincula cotidianamente con sujetos diversos. Este roce supone el desarrollo de una capacidad o inteligencia social que le permita pasar entre los distintos mundos comunitarios de modo efectivo. Tal transcurrir entre mundos consiste en reconocer distintas delimitaciones de significado y sentido que dan identidad a las diferentes comunidades. En ese roce cotidiano con lo diverso, el ser humano transcurre interfronterizamente entre regímenes diferentes de validación y contacto, por ellos requiere jugar entre lo diverso para insertarse en la aproximación intencional hacia el otro que habita en esa diversidad.

La aproximación al otro se da no desde mi situación comunitaria, sino desde la del otro, es decir desde lo que él exige para aceptar ser acercado. Con ello, por las condiciones mismas de la experiencia social, la interacción se torna tan compleja que debe seducirse al desconocido por medio de puentes de filiación, esos puentes son discursos del yo que se adecuan al otro en su forma de estar situacional. Los discursos de vinculación deben ser entendidos como moralmente neutros, pero poseedores de lógicas de vinculación que provocan que quien enuncia derive sus postulados no de razonamientos formales, sino de intereses extralógicos, emocionales, sexuales, 
es decir, integrales. Quien se vincula a otro recurre a una lógica no formal, no logocéntrica, sino más bien eurocentrada. ${ }^{9}$

Se estructura un discurso para traspasar entre los diversos mundos que coexisten en la misma sociedad. Se franquean abismos de clase, generación y religión. Lograr que los oídos de otros nos presten atención no es censurable, sino acto virtuoso de aquel que no se encierra en un solo lugar, sino que se abre al recorrido de muchos. Dentro de una misma sociedad impera el recelo preventivo hacia quienes son de otro modo. Lo vivimos cuando transitamos por otro barrio que no es el nuestro, o cuando visitamos una ciudad que no es la nuestra. El extrañamiento que padece nuestro espíritu no es solo el mío, sino también de quien me ve. En ese momento la vinculación con los extraños, los otros y yo se vuelve un reto que debe conducir al traspasar de los recelos y al disfrute de una rica danza de improvisaciones.

Solo el discurso vaciado de supuestos nos da tal fruto. La "mentira" y la "verdad" son en esa situación solo herramientas de una vinculación segura, que nos dirigen al placer de la compañía del otro receloso durante el tiempo que esta perdure. Se trata, en fin, de meros recursos a favor de los hombres para resolver la complejidad de las situaciones de su mundo. El mentir no es una suerte de perversión moral, o una omisión intencional, o de erróneo proceder al pesar y argumentar, sino el resultado social de una actitud de preservación de sí mismo y de la especie. La recurrencia a una interpretación situacional de la realidad y a una enunciación funcional al contexto de vinculación tiene fundamentos sociales, antropológicos y gnoseológicos. Carente de la comprensión de esto, la predominante lógica logocéntrica solo formaliza supuestos éticos de pensamiento valorativo, reduciendo todo su esfuerzo a un mero juego de lenguaje que hoy solo favorece el flactus vocei de un intelecto encerrado en sus propias miserias.

No hay verdad, no hay mentira, solo enunciados que estructuramos con base en perspectivas intencionales que responden a determinaciones superestructurales, no ontológicas, carentes por ello de sustento en la realidad, sino en las mediaciones que afectan tal vinculación. Fue Platón quien evidenció en su momento la esencia del problema: “...queremos una noble y gran mentira con la que mejor persuadiríamos a los gobernantes mismos

9 Es decir que gira en torno a la obtención de vínculos de intimación y filiación como categoría de la argumentación. 
y, si no, a los demás ciudadanos" (Platón, 1984, p. 87). El problema de la "mentira" y la "verdad", de su presencia en nuestras relaciones cotidianas y en la organización de la sociedad, es político, antes que moral, gnoseológico antes que epistemológico, erótico antes que lógico. Será entonces obligatorio desarrollar una nueva perspectiva respaldada en una teoría especial del poder y de la ideología, para dar cuenta de un tema que se origina en condiciones de respuesta neuronal a vivencias sociales transitorias y centralizaciones conductuales.

\section{Referencias}

Ekmann, P. (2009). Cómo detectar las mentiras. España: Paidós.

Navarro, R. (2012). El arte de mentir ¿Una necesidad del cerebro? España: Ensayo.

Nietzsche, F. (1973). Sobre la verdad y la mentira en sentido extra moral. Argentina: Decleê. Platón. (1984). La república. México: Porrúa.

Simmel, G. (2006). Sociología. España: Galaxia Gutemberg. 